\title{
Umbilical Artery Doppler as the Signature Vessel and Predictor of Perinatal Outcome in IUGR
}

\author{
Dr. Anjali Dathan ${ }^{1}$, Dr. Biju. P. R ${ }^{2}$ \\ ${ }^{I}$ (Department of Radiodiagnosis, Govt Medical College Palakkad, India) \\ ${ }^{2}$ (Department of Surgery, Govt Medical College Thrissur, India)
}

\begin{abstract}
Role of Doppler analysis of uteroplacental and fetal circulation in IUGR with respect to analyzing the immediate neonatal outcome and optimizing the time of delivery .

Introduction: The most common method to evaluate health in fetuses identified as small for gestational age(SGA) are the BPP and NST. Neither of these are sensitive in producing poor outcome in IUGR. So we use color Doppler for this. It has become the gold standard in the management of the growth restricted fetus ${ }^{13,14}$. In this study we use Doppler studies of umbilical artery, middle cerebral artery, uterine artery, and fetal aorta to identify IUGR fetuses and to avoid iatrogenic harm to them or their mothers

Materials and methods: This is a prospective study conducted at Government Medical College, Thrissur Kerala between July 2003 to September 2004. 100 singleton pregnancies were prospectively examined with Doppler ultrasound of UA, MCA, Ut A, FA.

Results: Of the 100 patients studied with clinical IUGR 83 had abnormal fetometry on ultrasound and abnormal Doppler findings. The res,t that is 17 patients had abnormal fetometry but normal Doppler findings on serial follow up.The most common risk factor detected was PIH

Umblical Artery: 99\% of Doppler cases showed high indices in the umbilical artery followed by 59\% in the uterine artery. Brain sparing effect was seen in 57\%. MCA PI was highly correlated with perinatal outcome. The sensitivity and specificity for Doppler test in relation to abnormal outcome in $82.3 \%$ and $44.5 \%$. Thus abnormal Doppler is associated with and is helpful in predicting adverse perinatal outcome.

Conclusion: The abnormal Doppler is associated with and is helpful in predicting adverse perinatal outcome

Keywords: Umbilical artery, Middle cerebral artery, Uterine artery, fetal aorta, Color Doppler
\end{abstract}

\section{Introduction}

Intrauterine growth retardation (IUGR) refers to a condition in which a fetus in unable to achieve its genetically determined potential size. A fetus affected by IUGR forms a subset of SGA. infants .A fetus is growth restricted or small gestational age if its weight is below the $10^{\text {th }}$ percentile for gestational age(Cunningham, Gant et al $)^{1}$.

The Doppler parameters like S/D ratio,RI and PI of uterine,umbilical and fetal vessels have been used for a long time to predict perinatal outcome.Fitzgerald and Drumm first reported the use of Doppler sonography to investigate the human circulation ${ }^{18}$ The first randomized clinical trial of Doppler ultrasound for antenatal surveillance ,reported in 1987 by Trudinger and co workers showed a decrease in caesarean sections for fetal distress in labour ${ }^{6}$.Since then multiple retrospective and prospective studies have shown that abnormal umbilical artery waveforms are associated with adverse outcome

A number of investigators-Arduini, Rizzo ${ }^{3}$ Trudinger BJ, Cooks CM, Giles $\mathrm{WB}^{6}$, MarsalK, Westergaard $^{8}$, Rochelson B, Divon and Schulman ${ }^{10}$., Mari,Deter RL ${ }^{11}$, Padmagirison R, Rai L ${ }^{14}$, Juan $\mathrm{M}$, Gonzalez $\mathrm{MD}^{13}$,Fleischer ${ }^{7}$ have examined the relationship between IUGR and abnormal umbilical artery flow velocity waveforms.

In 1991, Trudinger et al noted that patients with a progressive deterioration in the umbilical flow velocity waveforms over time had the least favorable perinatal outcome, a fivefold increase relative to those with normal waveforms.

In 1991 itself, Arduini et al noted that umbilical velocimetry was more effective than the NST for identifying fetuses at risk of adverse perinatal outcome ${ }^{12}$ In 2001-2002 Divon MY et al and Danti L,Trusca T et al correlated umbilical Doppler velocimetry and perinatal complications and the mortality in IUGR fetuses.In 2006-2007 Juan $\mathrm{M}^{13}$,Padmagirison,Rai ${ }^{14}$ et al studied the use of Doppler in predicting adverse perinatal outcome in IUGR.

Studies on the fetal MCA have been done by Wladimiroff ${ }^{15}$,Mari and Deter ${ }^{4}$,Rizzo and Caponi ${ }^{17}$ Arbeille and Ozcan ${ }^{16}$. Many studies were done on the uterine artery by Trudinger BJ,Fleischer ,Schulman H,Arduini,Rizzo et al .Fetal aorta has also been studied in detail by Griffin D,Nicolaides et al ${ }^{4}$

The most common methods to evaluate the SGA fetuses are BPP and NST , but neither of these are sensitive to predict poor outcome in IUGR. So color Doppler has a role here.Color Doppler has become the gold 
standard in the management of the growth restricted fetus ${ }^{13,14}$ due to this lack of sensitivity of BPP and NST to predict poor outcome and lack of any newer modalities that are as sensitive and specific as doppler especially the umbilical artery and middle cerebral artery Doppler values Over the years Doppler has retained its significance in predicting the prognosis and hence this investigation was chosen in our study.

\section{Materials And Methods}

This is a study conducted at Government Medical College, Thrissur, Kerala between July 2003 To September 2004 .

\subsection{Inclusion Criteria}

100 case of clinically and sonologically confirmed cases if IUGR in the maternal age group 18 -35 years, beyond 30 weeks of gestation. Gestational age (GA) determination was based on the best estimate from neonatal history, clinical gestational age or fetal biometry, preferably in first trimester. Patient demographic data and risk factors like hypertension, PIH, DM , previous abortions , any drug intake or infections, and the birth weight, nature of delivery and perinatal outcome were recorded.

\subsection{Clinical Assessment of IUGR}

Clinical criteria included those patients with a fundal height less than 4 weeks of the period of amenorrhoea. Ultrasound criteria included patients with a low volume of abdominal circumference (AC) below 2 standard deviation (SD) from mean value for GA. IUGR is diagnosed if sonographic predictors reflect an age significantly reduced from expected or an effective fetal weight less than the $10^{\text {th }}$ percentile. Fetal biometric values, placental growth, amniotic fluid volume and EFW all help to enhance diagnosis

A total of 100 patients were included. Doppler evaluation was conducted on 4 vessels that is umbilical artery, uterine artery, fetal aorta and fetal middle cerebral artery with repeats at frequent intervals for the high risk group .

Studies were performed using a real time .Color Doppler ultrasound machine - ATL (ATL- APOGEE 800) in the Department of Radio diagnosis medical college Thrissur with all cases kept till confinement and outcome of the pregnancy noted in detail including intra uterine demise (IUD), nature of labour,perinatal or neonatal death with weight and APGAR score of the baby .

\subsection{Statistical Analysis was done}

Statistical analysis was using Chi-square test, Students T-test ,Snedcors F-test and the coefficient of variation were also studied.

\section{Results}

Among the 100 patients studied $23 \%$ of case in multigravida had previous bad obstetric history like previous lower segment caesarean section, Abortion ,PIH , IUGR , and Neonatal death .63\% of the abnormal Doppler cases show one or other risk factor especially pregnancy induced hypertension (PIH) PIH is shown in more than $50 \%$ of the cases.

Among the 100 patients considered,17 show normal doppler (now onwards "normal") and 83 show abnormal Doppler (now onwards "abnormal")

The average age of the patients considered is 25.62 with a standard deviation of 4.61.It is found that the age does not make any considerable effect on the abnormality in Doppler.In the parity /gravida status it is seen that most of the cases belong to primi(about $60 \%$ of the case study)and another $30 \%$ come in G2.(second gravida).Considering BP as a risk factor ,high BP is not that prevalent in the normal Doppler cases $(11 \%$ with a value of 130/80) but in the abnormal Doppler cases ,more than 50\% have a high BP ranging upto 180/110-130. In fetometry decreased $\mathrm{AC}$ is related more to abnormal Doppler as is also the decreased liquor volume.

On studying the mode of delivery, there is significant difference observed in the number of emergency LSCS and full term normal delivery (FTND).In the case of normal Doppler , there is more than four times FTND observed compared to abnormal Doppler (59\%/14\%)67\% undergo LSCS in abnormal doppler(emergency and elective).In the normal Doppler cases only $12 \%$ is in need of induced vaginal delivery while $19 \%$ of cases of induced vaginal delivery are found in the abnormal Doppler.

The occurrence of preterm babies is in the ratio 1:2 in the normal and abnormal Doppler using Chi square test,p value $0.9392>0.05$ and in case of term babies $\mathrm{p}$ value $0.9614>0.05$.Thus more of preterm babies in the abnormal Doppler ( $>50 \%$ of the babies are preterm).In the normal Doppler $82 \%$ of cases are normal deliveries ,5\% of IUD are seen in the abnormal doppler cases .Neonatal death is almost double and ICU admission is very high(12\% in normal and $34 \%$ in abnormal).

The change of S/D,RI and PI in the abnormal Doppler is significant compared to normal Doppler.The S/D increases from 2.91 to 4.15 in the umbilical artery and from 2.04 to 2.77 in the uterine artery and from 6.27 
to 6.48 in the fetal aorta but changes from 4.16 to 3.62 in the MCA.Thus abnormal Doppler shows a decline in the MCA values which correlates with the brain sparing effect. (Table-2)

In case of AEDV usually brain sparing is found.The serious findings in abnormal Doppler shows a majority of high indices in the umbilical artery, with $99 \%$ abnormal patients followed by high indices in the uterine artery (59\%) and brain sparing effect in 57\% of cases. Only $1 \%$ shows REDV.(Table-3)

\section{Significance of doppler indices on the outcome}

Compared to the outcome in the normal Doppler there are no severe outcomes of NND or IUD observed in the normal Doppler and only ICU admission is seen (12\%) as the changes of S/D,RI and PI in normal doppler are not highly significant.So the ICU admission can be treated as due to other reasons.

However in the case of abnormal Doppler there is considerable outcome in the IUD,NND and ICU admissions $(5,11,34 \%)$ because there are significant changes (increase in umbilical artery,uterine artery and fetal aorta for S/D,RI and PI is seen and it is decreased moderately in the MCA.

Table 1 Patient data

\begin{tabular}{|c|c|c|}
\hline Parameter & Normal Doppler & Abnormal Doppler \\
\hline $\mathrm{n}$ & 17 & 83 \\
\hline Age ( Mean \pm SD) & $25.7 \pm 5.587$ & $25.6 \pm 4.43$ \\
\hline Birth weight ( Mean \pm SD) & $2.25 \pm 0.40$ & $1.96 \pm 5.1$ \\
\hline Parity- & Percentage & Percentage \\
\hline Primi & 58.82 & 60.24 \\
\hline G2 & 29.41 & 30.12 \\
\hline G3 & 11.76 & 6.02 \\
\hline G4 and Above & 0 & 3.61 \\
\hline \multicolumn{3}{|l|}{ Risk Factors } \\
\hline $\mathrm{PIH}$ & 11.76 & 50.60 \\
\hline$\overline{D M}$ & 0 & 3.61 \\
\hline Anaemia & 5.88 & 3.61 \\
\hline Heart Disease & 0 & 3.61 \\
\hline Epilepsy & 0 & 1.20 \\
\hline \multicolumn{3}{|l|}{ Fetometry } \\
\hline $\mathrm{D} / \mathrm{BPD} / \mathrm{HC}$ & 0 & 2 \\
\hline $\mathrm{D} / \mathrm{BPD}$ & 0 & 6 \\
\hline $\mathrm{D}$ & 17 & 75 \\
\hline \multicolumn{3}{|l|}{ Liquor Volume } \\
\hline Normal & 0 & 6 \\
\hline Adequate & 0 & 6 \\
\hline Decreased & 17 & 71 \\
\hline \multicolumn{3}{|l|}{ Mode of Delivery } \\
\hline Emergency LSCS & 29.5 & 56.6 \\
\hline Elective LSCS & 0 & 9.6 \\
\hline Induced vaginal & 11.8 & 19.3 \\
\hline FTND & 58.8 & 14.5 \\
\hline \multicolumn{3}{|l|}{ Outcome } \\
\hline Intra Uterine Demise & 0 & 5 \\
\hline Neonatal Death & 1 & 10 \\
\hline Preterm & 4 & 48 \\
\hline ICU Admission & 2 & 31 \\
\hline Normal (FTND) & 14 & 46 \\
\hline
\end{tabular}

D-decreased abdominal circumference, BPD- decreased biparietal diameter HC-decreased head circumference

Table 2: Table showing the S/D, RI, PI of normal and Abnormal Doppler Patients

\begin{tabular}{|l|l|l|l|l|l|l|}
\hline & Normal & Abnormal \\
\hline Vessels & S/D & RI & PI & S/D & RI & PI \\
\hline & Mean \pm SD & Mean \pm SD & Mean \pm SD & Mean \pm SD & Mean \pm SD & Mean \pm SD \\
\hline UA & $2.91 \pm 0.41$ & $0.65 \pm 0.06$ & $1.41 \pm 0.22$ & $4.15 \pm 1.148$ & $0.72 \pm 0.07$ & $1.58 \pm 0.24$ \\
\hline MCA & $4.16 \pm 0.87$ & $0.74 \pm 0.05$ & $1.81 \pm 0.38$ & $3.62 \pm 0.93$ & $0.71 \pm 0.08$ & $1.56 \pm 0.38$ \\
\hline UtA & $2.04 \pm 0.34$ & $0.51 \pm 0.08$ & $1.33 \pm 0.23$ & $2.77 \pm 0.92$ & $0.61 \pm 0.11$ & $1.51 \pm 0.38$ \\
\hline Aorta & $6.27 \pm 0.51$ & $0.83 \pm 0.15$ & $2.07 \pm 0.33$ & $6.48 \pm 0.98$ & $0.79 \pm 0.09$ & $2.01 \pm 0.39$ \\
\hline
\end{tabular}

Table 3: Severe Doppler Abnormality

\begin{tabular}{|l|l|l|l|l|l|l|}
\hline & AEDV & REDV & Brain Sparing & High indices in arteries & Aorta \\
\cline { 5 - 7 } & & & & Umbilical Artery & Uterine Artery & A \\
\hline \% of cases & 12 & 1 & 57 & 99 & 59 & 29 \\
\hline
\end{tabular}

AEDV: Absent End Diastolic Velocity, REDV: Reduced End Diastolic Velocity 
Table 4: Effect of AEDV/REDV on the perinatal outcome

\begin{tabular}{|l|l|l|l|l|}
\hline & IUD & NND & ICU & HD \\
\hline AEDV & 4 & 4 & 6 & 1 \\
\hline REDV & 1 & 0 & 0 & 0 \\
\hline
\end{tabular}

Table 5: Sensitivity, specificity and predictive values of Doppler on the outcomes

\begin{tabular}{|c|c|c|c|c|c|}
\hline & \multicolumn{2}{|l|}{ Normal } & \multicolumn{2}{|l|}{ Abnormal } & Total \\
\hline Outcome normal & \multicolumn{2}{|l|}{14} & \multicolumn{2}{|l|}{46} & 60 \\
\hline Outcome abnormal & \multicolumn{2}{|l|}{3} & \multicolumn{2}{|l|}{37} & 40 \\
\hline Total & \multicolumn{2}{|l|}{17} & \multicolumn{2}{|l|}{83} & 100 \\
\hline Sensitivity & Specificity & +ve predictive value & -ve predictive value & $\%$ false - ve & $\%$ false + ve \\
\hline 82.35 & 44.57 & 23.33 & 92.5 & 17.64 & 55.42 \\
\hline
\end{tabular}

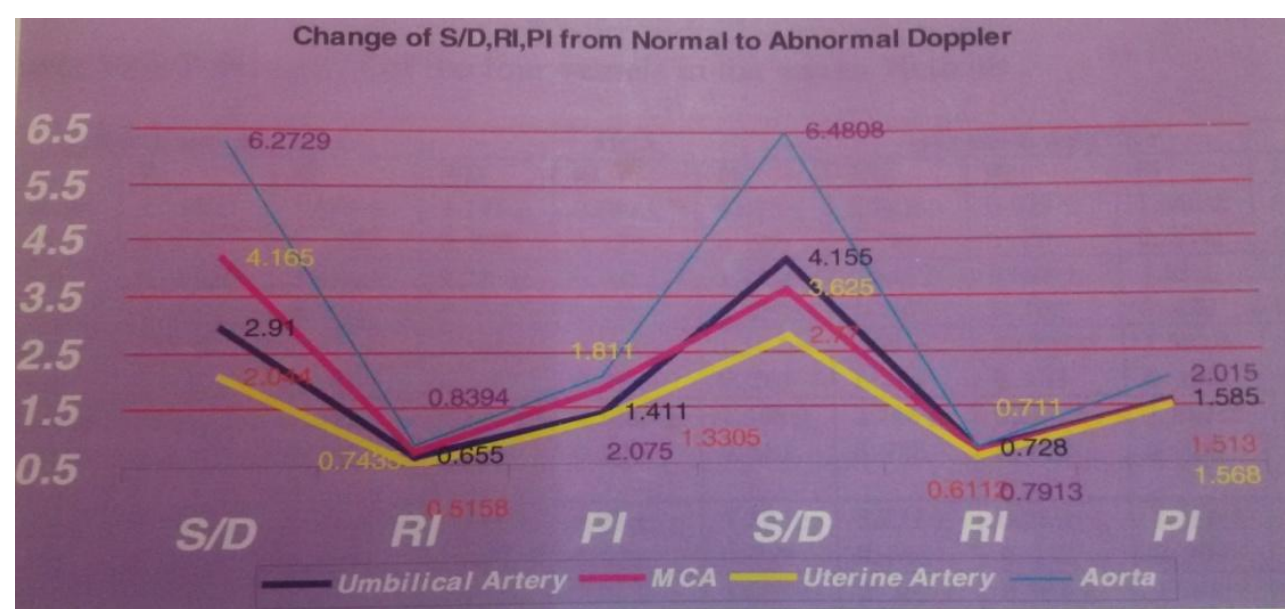

\section{Discussion}

IUGR as described earlier is a condition in which the fetus is unable to achieve its genetically determined potential size or an effective fetal weight (EFW) less than the $10^{\text {th }}$ percentile for that gestational age .

\subsection{Doppler in IUGR}

In our study a total of 100 patients with clinical IUGR were studied. Of the 100,83 had both abnormal fetometry and Doppler findings. 17 patients had abnormal fetometry but normal Doppler findings on serial follow up. The last Doppler result prior to delivery was used for analysis

\subsection{Uterine artery}

Uterine arteries reflect the uteroplacental flow. It normally changes from one of low peak flow velocity and early diastolic notch to one of high peak flow and no diastolic notch by $18-22$ weeks. Pulsatality index more than 1.45 and presence of early diastolic notch ${ }^{2,3}$ in bilateral uterine arteries at 18-22 weeks is suggestive of uteroplacental insufficiency .

There are 9 case of uterine artery notching in the 83 abnormal Doppler cases. In our study the sensitivity of the association of uterine notching with $\mathrm{PIH}$ is $88.8 \%$ with a specificity of $54.05 \%$ similar to studies by Trudinger BJ et al. The sensitivity of an abnormal RI (more than 0.58 ) in gestational age in detecting abnormal outcome in our study is $68.18 \%$, specificity $46.42 \%$ positive predictive value (PPV) of 50 $\%$ and negative predictive value (NPV) of $65 \%$ similar to Jacobson et $\mathrm{al}^{37}$. The sensitivity of a high S/D in the uterine artery and its specificity in detecting abnormal outcome (73.68\% and $58.14 \%$ ) with PPV of $70 \%$ and NPV of $62.5 \%$. similar to a study by Valensise et $\mathrm{al}^{2}$, Campbell et $\mathrm{al}^{4}$

\subsection{Umbilical Artery}

Umbilical artery is a direct reflection of flow in placenta - SIGNATURE VESSEL Normal value of S/D ratio in umbilical artery

\section{S/D ratio $<3$ by 28 weeks}

\section{S/D ratio $<2.8$ by term}

An S/D ratio $>2$ standard deviation (SD) above normal, is considered abnormal or an S/D ratio >3 after 30 weeks of gestation is considered abnormal . Pulsatility index (PI) $>2$ standard deviation above the mean for gestation age is considered abnormal

A numbers of investigators : - Trudinger ${ }^{6}$, Fleischer ${ }^{7}$, Marsal $^{8}$, Arduini ${ }^{5}$,Divon and Schulman ${ }^{2}$ have examined the relationship between intra uterine growth retardation and abnormal umbilical artery flow velocity 
waveforms. In normal fetuses the pulsatality index decreases with advancing gestation . In fetuses with IUGR there is an increase in PI secondary to the decrease , absence or reversal of end diastolic flow and is associated with adverse perinatal outcomes. The sensitivity of umbilical artery flow waveform in relation to abnormal outcomes ranged from 22-100\%, specificity from 83 to $95 \%$ and negative predictive accuracy from $68-100 \%$ and positive predictive accuracy from 50-81\%. The sensitivity and specificity of an S/D ratio > 3 in the umbilical artery in detecting abnormal outcome is $93.3 \%$ and $45.8 \%$ in our study similar to Gramellini et al ${ }^{9}$. $12 \%$ of cases show absent end diastolic velocity (AEDV) in umbilical artery and are associated with various complication like IUGR, neonatal death (NND) and ICU admission - preterm, low birth weight (LBW) babies. Usually AEDV is associated with brain sparing; one case was associated with VSD similar to studies by Taylor et $\mathrm{al}^{2}$, Rochelson $\mathrm{B}$ et $\mathrm{al}^{10}$ ) In our study of the 10 AEDV cases 7 are leading to perinatal mortality and $70 \%$ chance of mortality is found in AEDV cases . 6 cases with absent / reduced end diastolic velocity (REDV) $(54.54 \%)$ went into emergency CS similar to studies by Divon et $\mathrm{al}^{9}$

\subsection{Ductus Venous (dv)}

Of the above mentioned 10 AEDV of umbilical artery cases 3 showed DV reversal and associated with $100 \%$ chances of perinatal mortality

\subsection{Middle Cerebral Artery}

Vasodilatation in MCA is a surrogate marker of hypoxia. There is an association between abnormal MCA PI and adverse perinatal and neurological outcomes. The CPR is derived by dividing MCA PI by umbilical artery PI and incorporates data of both placental status (GA) and fetal response (MCA) in prediction of abnormal outcomes. It is considered abnormal below 1.08. MCA pulsatility index (PI) shows remarkable correlation with perinatal outcome .

\subsection{AORTA}

Abnormal outcomes in terms of aorta can be assessed generally in abnormal Doppler with an average S/D of $>7.5$. The aorta indicates that $50 \%$ of cases show abnormal outcome in Doppler analysis. Gudmundsson, Marsal K etal noted that the finding of absent or reversed end diastolic velocity in the fetal aorta in associated with an adverse outcome of pregnancy and increased neonatal morbidity ${ }^{12}$

\section{Conclusion}

Fetometry is the most sensitive and specific method (100\%) in the detection of IUGR. The ideal time to screen for IUGR is after 24 weeks gestational age. The most commonly identified risk factor in IUGR is PIH. The most common serious findings in Doppler study include high indices in umbilical artery (99\%) high indices in uterine artery (59\%) and brain sparing effect (57\% of cases ). A severe grade of abnormality in Doppler analysis change determined by absent or reversed end diastolic flow in the umbilical artery is invariably associated with the increased perinatal mortality and morbidity. The sensitivity and specificity of Doppler test in relation to abnormal outcome is $82.3 \%$ and $44.5 \%$. An umbilical artery S/D ratio $>3$ in associated with adverse perinatal outcome (sensitivity $93.3 \%$, specificity $45.8 \%$ ). The sensitivity and specificity of the association of uterine notching with PIH are $88.8 \%$ and $54.05 \%$. The presence of reversed flow in DV is an aminous sign and showed $100 \%$ sensitivity and specificity in adverse neonatal outcome

Clinicians challenge is to identify the IUGR fetuses at risk and follow up with Doppler analysis to help assess prognosis and timely intervention. The role of Doppler is shifting from curative to preventive perspective to prolong pregnancy and to reduce perinatal morbidity and mortality

\begin{tabular}{lll}
\multicolumn{2}{l}{ Abbreviations } & \\
UA & $:-$ & Umbilical Artery \\
MCA & $:-$ & Middle Cerebral Artery \\
Ut A & $:-$ & Uterine Artery \\
FA & $:-$ & Fetal Aorta \\
PI & $:-$ & Pulsatility Index \\
LBW & $:-$ & Low Birth Weight \\
SGA & $:-$ & Small for Gestational Age \\
IUGR & $:-$ & Intra Uterine Growth Retardation \\
DV & $:-$ & Ductus Venosus \\
BPP & $:-$ & Biophysical profile \\
NST & $:-$ & Non stress Test \\
GA & $:-$ & Gestational Age
\end{tabular}




\section{References}

[1]. Cunningham FG, Gant NF, Leveno Williams Obstetrics $20^{\text {th }}$ Edition, Chapter 36 Page No $839-850$

[2]. Harold Schulman and Zeev Weiner in Clinical applications of Doppler ultrasound $2^{\text {nd }}$ edition . Edited by KJW Taylor P.N Burns and P.N.T Wells . Raven press Ltd Newyork 1995chapter 12; page No 255.

[3]. Arduini D, Rizzo G, Romanini $\mathrm{C}$ et al .Uteroplacental blood flow velocity waveforms as predictors of pregnancy induced hypertension Eur. J. Obstet Gynecol Reprod Biol 1987 December ; 26(4) ; 335-41

[4]. Copel JA ,Reed KL Doppler ultrasound in Obstetrics and Gynecology Raven press Ltd New York 1995

[5]. Arduini D, Rizzo G, Umbilical artery velocity waveform in early pregnancy . A trans vaginal color Doppler study J clinical ultrasound 199; 19: 335-339.

[6]. Trudinges BJ, Cook CM, Giles WB et al ; Umbilical artery flow velocity waveform in high risk pregnancy ; Randomized controlled trial - Lancet $1 ; 188-190,1987$

[7]. Fleischer AC, Manning FA, Jeanty P, Romero R, Sonography in obstetrics and gynecology principles and practice $5^{\text {th }}$ edition, Prentice - Hall - International Inc

[8]. Marsal K, Westergaard HB, Lingman G etal .A critical appraisal of the use of umbilical artery Doppler ultrasound in high risk pregnancies ; use of meta -analysis in evidence based obstetrics .Ultrasound obstet gynecology 2001 June 17 (6) 466-76

[9]. Gramellini D, Folli MC, Raboni S et al (1992) Cerebral umbilical Doppler ratio is a predictor of adverse perinatal outcome. Obstet gynecology $79 ; 416-420$

[10]. Rochelson B, Schulman H , Farmakides G et al : The significance of absent end diastolic velocity in umbilical artery velocity waveform ,Am J .Obstet gynecology ; 1987 ; $156: 1213-1218$

[11]. Mari G, Deter RL Middle cerebral artery flow velocity waveform in normal and small for gestational age fetuses Am J Obstet gynecol $1992 ; 166: 1262-1270$

[12]. Maulik D , Doppler ultrasound in Obstetrics and Gynecology $1^{\text {st }}$ edition 2003 reprint Springer - Verlag publications ,New York

[13]. Relationship between abnormal fetal testing and adverse perinatal outcomes in intra uterine growth restriction .Juan M , Gonzalez MD, David M Stansilio MD, MSCEI and MD ,Serdar Ural MD, George A ,Macenes MD, MSCEZ Anthony O ,Odiho MD, MSCE 1 2. American Journal of Obstetrics and Gynecology - Volume 196, issue 5 (may 2007 )

[14]. Padmagirison R, Rai L , Fetal Doppler verses NST as predictors of adverse perinatal outcome in severe preeclampsia and fetal growth restriction J.Obslet Gynecol $2006 ; 56: 134-8$

[15]. Wladimiroff JW,Stewart PA-Doppler ultrasound assessment of cerebral blood flow in the human fetus .Br.J.Obstet Gynecol 1986:93:471

[16]. Ozcan T,Sbracia M et al.Arterial and venous Doppler velocimetry in the severely growth restricted fetus and associations with adverse perinatal outcome.Ultrasound in Obstetrics and Gynecology 1998 Jul:12(1):39-44.

[17]. Rizzo,Caponi et al. The value of the fetal arterial, cardiac and venous flows in predicting $\mathrm{pH}$ and blood gases measured in umbilical blood at cordocentesis in growth retarded fetuses -British Journal of Obstetrics and Gynecology-December 1995.vol-102:963-969.

[18]. Fitzgerald DE,Drumm JE.Non invasive measurement of the fetal circulation using ultrasound:A new method.BMJ.1977:2:14501451 